\section{The Secret Formula for Choosing the Right Next Role}

KATE MATSUDAIRA
THE BEST

CAREERS ARE NOT DEFINED BY TITLES OR RESUME BULLET POINTS.
C hanging jobs-especially the higher up you get in your career-is a complex process. There are so many factors to consider, and often the factors that stand out most are the ones that matter the least: fancy titles, exciting projects, tempting promises of future success...

But those factors that seem so valuable in the moment are just that-they are momentary. Your career isn't just about this one next step you're taking. Your career is a journey that will last a long time.

It is smarter to invest in your long-term success. Focus on factors that will increase your career capital and make you a more valuable hire in your next role, and the one after that, and the one after that.

When you are looking at the options for your next role, there are smarter choices that you can make. Here are the most important factors to consider when picking your next opportunity.

PICK A GOAL, NOT A TITLE

A title looks good on a resume, and might pump up your ego a little bit, but making

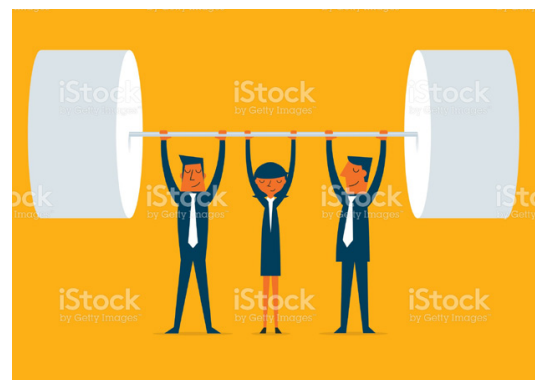
your job title a serious 
factor in your job search is a big mistake.

Your title is so much less important than the work you do and the skills you develop while in a role. Those hiring you for your next role will know that. They might see that you were a VP in your last job, but if you don't have any results or skills to show for it, you won't stand out among the many other candidates who were also VPs in their last jobs.

If you want to be truly successful, then your career path should be about acquiring skills and accomplishments, not just upgrading to shinier and fancier titles.

First of all, different titles mean different things in different companies. I have been everything from VP and CTO at successful startups to CEO of my own company, but after years of having executive-level titles, I took a role without one.

If I had rejected that job opportunity because the title was lower than any that I had had in the previous 10 years, I would have missed out on one of the biggest, most lifechanging growth opportunities that I have ever had.

Moreover, in that role, instead of being a software engineer I was in the job category of TPM (technical program manager]. I had never been a TPM before, and to be honest, it was not a role I identified with. No one would describe me as organized, and I didn't have the background skills; I write code and lead engineering teams.

Even though the title was a demotion, and it was a job family that didn't fit, I still took the position because of what I could gain from it.

Yes, I had to learn some TPM skills, but what was truly valuable about that job was the access it gave me. Because 


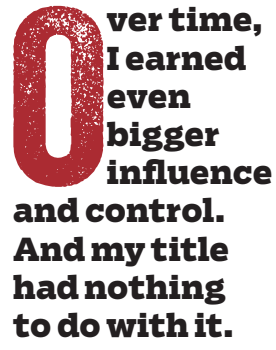

of what my team was focused on, I got to be in meetings with top executives who were running 1,000-plus-person teams. I was presenting to VPs who had decision-making power for a huge organization.

I had a huge scope. Instead of being siloed in one department where I was the boss, I was able to get on the radar of key leaders throughout the organization. I was able to gain influence and visibility; I saw the priorities for the whole company (not just my department], which allowed me to align myself with the most important work being done.

I got to learn, and I gained visibility. I built my network and got to know many people in the organization as a whole. Over time, I earned even bigger influence and control. And my title had nothing to do with it.

When you are looking at different job opportunities, think about the bigger picture for your career. Where do you want to be in 10 years? What is your ultimate career goal?

This is different for everyone. Think about where you want to end up, and work backwards from there. What skills do you need in order to get there? What steps will you need to take along the way?

Focusing on the short-term win of getting a fancy title or bigger paycheck is a mistake. If a job isn't actively putting you into the situations you need in order to grow or make the right contacts, then it is not really the right choice. It will delay you getting where you need to go.

When you're looking at an opportunity, consider whether this role will help you level up your career. Ask yourself the following questions: 
$\Rightarrow$ What skills do I still need to build in order to make progress toward my goals?

$\Rightarrow$ What benefits will the job afford me that maybe aren't visible in the job description?

$\Rightarrow$ Who will I meet?

$\Rightarrow$ What is this job setting me up for?

$\Rightarrow$ What will I have gained from this role in two years, and are those gains valuable to me?

PICK PEOPLE, NOT PROJECTS

Another easy trap to fall into when picking your next job is to focus too much on the projects you think you will get to work on.

Of course, we all want to work on things that are interesting and exciting or that could make us rich and famous. The truth is that projects get cancelled all the time. They change and become less exciting. The roles within them change, and you could end up doing legwork that isn't actually that interesting or exciting to you.

In college, I got a job working in a lab. I was so happy because I was envisioning myself working on exciting experiments and getting my work published in major journals. While those exciting projects did happen in this lab, I never got to do them. I ended up running the same experiment day after day, collecting the same data over and over again. This is often what research is-you need to make sure any results are statistically significant, so you do the same thing repeatedly.

The projects the lab was working on were exciting, but my life in the lab was not.

It is so important to consider what your day-to-day life 
will be like in a role. What will you actually spend your time doing? Will it add value to your career? What will you get the chance to learn?

Remember, when you are new to a team, you have no career capital built up with this organization. Career capital is your currency at work; when you provide a lot of concrete, visible value to the team or the organization, you have more leverage to do the things you want, such as work on the most exciting projects or get more flexibility in your schedule.

When you are new, you haven't earned this leverage. That means if you are assigned to a boring role on an exciting project, you pretty much just have to do it. Sometimes that can be OK (maybe you actually wanted to learn this boring skill because it will help you get a job you want in the future), but if it's not, then you are just stuck.

For example, I have a friend who really wanted to work on machine learning, so he joined a team doing that type of work. For the first year and half he didn't get to do anything related to machine learning, and instead was stuck writing deployment scripts and updates to data loaders-work that was much less interesting to him than the project he was on previously.

Projects are never guaranteed, so make sure you understand the specifics and exactly what work you will get the chance to do. Also, instead of thinking just about the work, I recommend thinking also about whom you will be working with.

Basing your decision on the people you will be working with is one of the best ways to pick a job. If you have to choose between an exciting project or a great team, 
always go for the great team.

Ninety-nine percent of my happiness in a job has to do with who my manager and coworkers are. I bet it is the same for you. You spend so much time at work; if you work full time, you probably spend as much [or more] time with your coworkers than you do with your friends or family.

In some organizations, it is common to interview with the boss and at least one other member of the team, though this doesn't always happen. You should always ask for the opportunity to meet more of the people you will be working with.

This has a few benefits:

$\Rightarrow$ You can meet with the people you will work with every day. Not only will you get a feel for what it will be like working with them, you can also ask them for insight into other aspects of the role. Do they like working there? How much turnover is there on the team? How does collaboration work? Does leadership listen to input on decisions? What are the things they would want to change about the team/companylculture? Why do they work there vs. anywhere else?

$\Rightarrow$ Your coworkers will feel invested in your success if they are part of the process of hiring you. Think about it-if you met with a candidate you liked and fought for him or her to be hired, wouldn't you be extra invested in that new hire doing well once he or she joined the team? Even a minimal investment will have a psychological impact on your potential coworkers. If they meet you or interview you, they will have already invested some amount of time in you and will be more inclined to want to see that investment rewarded. 
$\Rightarrow$ You won't be "brand new" on your first day. As humans, we are naturally resistant to change and new people whom we know nothing about. If you show up on your first

\section{Related articles}

$\Rightarrow 10$ Ways to Be a Better Interviewer Kate Matsudaira

Plan ahead to make the interview a successful one.

https:/lqueue.acm.org/detail.cfm?id=3125635

$\Rightarrow$ Avoiding Obsolescence

Kode Vicious

Overspecialization can be the kiss of death for sysadmins.

https:/lqueue.acm.org/detail.cfm?id=1781175

$\Rightarrow$ A Generation Lost in the Bazaar

Poul-Henning Kamp

Quality happens only when someone is responsible for it.

https:/lqueue.acm.org/detail.cfm?id=2349257 day having met no one yet, you are a stranger; your coworkers are more likely to see you as an "outsider" taking up space. Even a short meeting in advance will prime them to see you as familiar the next time you see them. Plus, you will have some baseline knowledge about the team that can help you fit in more quickly, as opposed to starting to learn about the team culture after you've joined.

\section{BE SMART WHEN YOU} CHOOSE YOUR NEXT ROLE When you are searching for the next step in your career, don't just think about the surface-level benefits. Drill down on your biggest goals and do a little thinking about whether or not each job will help you get closer to those goals.

The best careers are not defined by titles or resume bullet points. The smarter you are about what you choose next, the closer you will get to the things you truly want from your life and your work. 
Kate Matsudaira is an experienced technology leader. She worked in big companies such as Microsoft and Amazon and three successful startups (Decide acquired by eBay, Moz, and Delve Networks acquired by Limelight] before starting her own company, Popforms (https:I/popforms.com/), which was acquired by Safari Books. Having spent her early career as a software engineer, she is deeply technical and has done leading work on distributed systems, cloud computing, and mobile. She has experience managing entire product teams and research scientists and has built her own profitable business. She is a published author, keynote speaker, and has been honored with awards such as Seattle's Top 40 under 40. She sits on the board of acmqueue and maintains a personal blog at katemats.com.

Copyright $@ 2018$ held by ownerlauthor. Publication rights licensed to ACM. 